\section{Disagreement of diameter} and volume measurements for pulmonary nodule size estimation in CT lung cancer screening

\section{ABSTRACT}

We studied 2240 indeterminate solid nodules (volume $50-500 \mathrm{~mm}^{3}$ ) to determine the correlation of diameter and semi-automated volume measurements for pulmonary nodule size estimation. Intra-nodular diameter variation, defined as maximum minus minimum diameter through the nodule's center, varied by $2.8 \mathrm{~mm}$ (median, IQR:2.2-3.7 $\mathrm{mm}$ ), so above the $1.5 \mathrm{~mm}$ cutoff for nodule growth used in Lung CT Screening Reporting and Data System (Lung-RADS). Using mean or maximum axial diameter to assess nodule volume led to a substantial mean overestimation of nodule volume of $47.2 \%$ and $85.1 \%$, respectively, compared to semiautomated volume. Thus, size of indeterminate nodules is poorly represented by diameter. Trial registration number Pre-results, ISRCTN63545820.

\section{INTRODUCTION}

Most lung cancer screening guidelines, including Lung CT Screening Reporting and Data System (Lung-RADS), ${ }^{1}$ are based on pulmonary nodule size at first detection. Nodule size is defined as the mean diameter based on the average of length and width on axial CT images, assuming that a nodule can be fairly represented by a sphere. Since pulmonary nodules usually are not perfectly geometrically shaped, errors in nodule sizing may result. This particularly concerns nodules with a non-smooth margin, ${ }^{2}$ which more frequently turn out to be malignant than smooth nodules. ${ }^{3}$ Moreover, by using this measurement technique, only nodule growth on the axial plane is considered.

An alternative method, which has been applied by several European lung cancer screening trials, is to measure nodule volume semiautomatically using software. ${ }^{4}$ This enables an accurate estimation of nodule size via contour finding of the lesions after three-dimensional (3D) reconstruction.

For subsequent screenings, nodule management is based on nodule growth. In current US guidelines, growth is either defined as a fixed increase of $1.5 \mathrm{~mm}$ in nodule diameter regardless of the screen interval and nodule size, ${ }^{1}$ or based on the volume-doubling time (VDT) calculated using diameter-based estimation of nodule size. ${ }^{6}$ We hypothesised that, due to non-sphericity of pulmonary nodules, nodule size cannot be estimated accurately based on nodule diameter measurements. The purpose of this study was to evaluate the agreement of diameter and semiautomated volume measurements for pulmonary nodule size estimation in low-dose CT (LDCT) lung cancer screening.

\section{METHODS}

This study was performed using data of the Dutch-Belgian Randomised Lung Cancer Screening Trial (Dutch acronym: NELSON), a multicentre, randomised controlled lung cancer screening trial (trial registration number ISRCTN63545820). All non-calcified solid intermediate-sized nodules $\left(50-500 \mathrm{~mm}^{3}\right.$, ie, indeterminate cancer risk) from the baseline screening found in Dutch participants in which LungCARE (version Somaris/5 VA70C-W; Siemens Medical Solutions, Erlangen, Germany) could assess diameters and volume were included. Details regarding the study participants, imaging acquisition/analysis, nodule measurements and statistical analysis are provided in the online supplement.

\section{RESULTS}

Range in nodule diameter

At baseline, 1500 Dutch participants had 2240 non-calcified solid

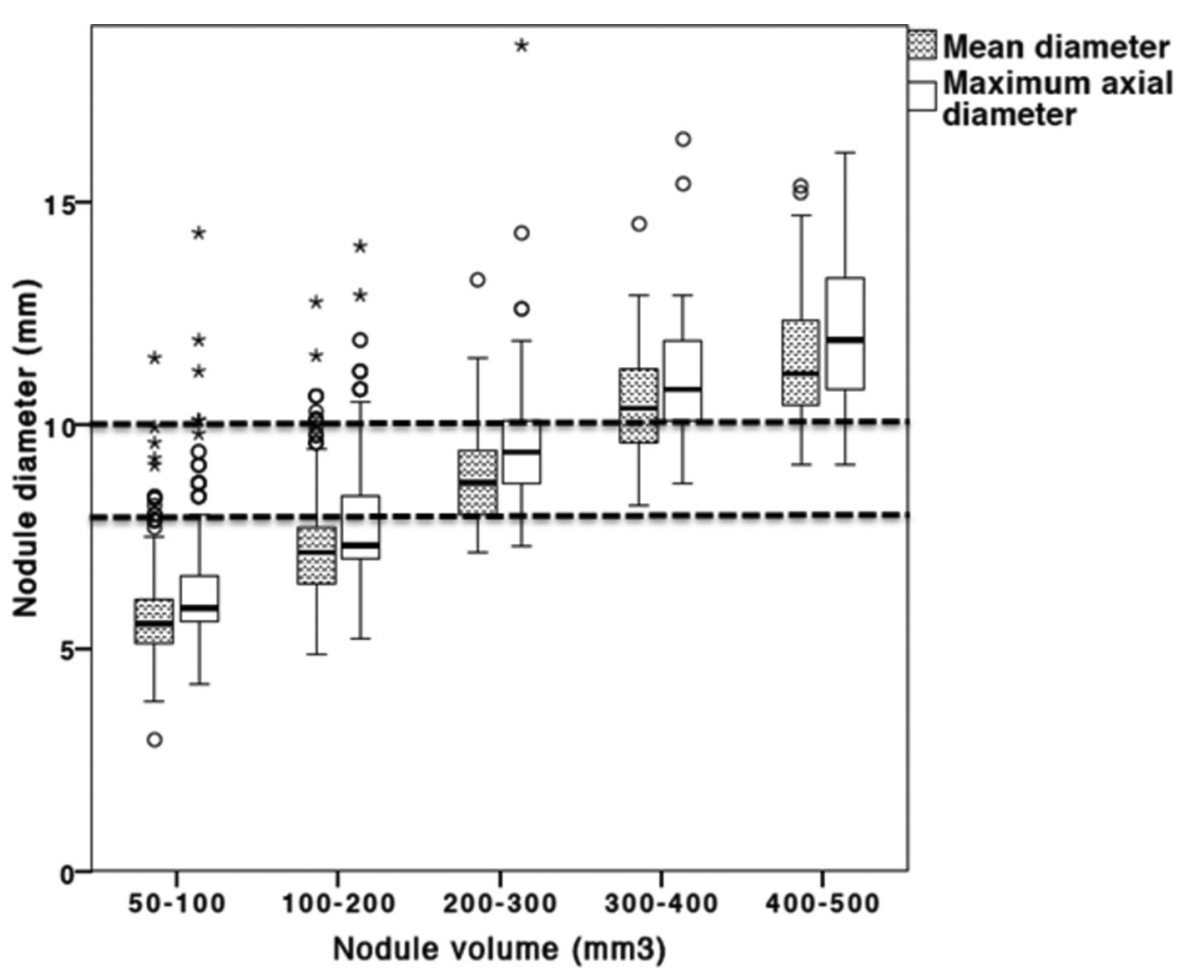

Figure 1 Range in nodule diameter per nodule volume category. Nodules with diameter between 8 and $10 \mathrm{~mm}$ (dotted lines) are represented in each volume category. The majority of the intermediate-sized nodules had a volume of $50-100 \mathrm{~mm}^{3}(\mathrm{n}=1423 ; 63.5 \%)$. A quarter (550 nodules, $24.6 \%$ ) were $100-200 \mathrm{~mm}^{3}, 159$ nodules $(7.1 \%)$ were $200-300 \mathrm{~mm}^{3}, 68$ nodules $(3.0 \%)$ were $300-400 \mathrm{~mm}^{3}$, and 40 nodules $(1.8 \%)$ were $400-500 \mathrm{~mm}^{3}$.

intermediate-sized nodules. The median volume was $82.4 \mathrm{~mm}^{3}$ (IQR: 62.9$\left.125.4 \mathrm{~mm}^{3}\right)$. The median nodule diameter was $6.1 \mathrm{~mm}$ (IQR: $5.4-7.2 \mathrm{~mm}$ ) based on mean diameter measurements, and $6.6 \mathrm{~mm}$ (IQR: $5.9-7.7 \mathrm{~mm}$ ) based on maximum axial diameter measurements. The range in nodule diameter per nodule volume category is shown in figure 1. Nodules with diameters of $8-10 \mathrm{~mm}$ were represented in each volume category.

\section{Intranodular diameter variation}

The minimum nodule diameter in any direction for the 2240 solid intermediate-sized nodules ranged from 2.1 to $14.5 \mathrm{~mm}$; the maximum nodule diameter in any direction ranged from 4.9 to $20.1 \mathrm{~mm}$. The median intranodular diameter variation was $2.8 \mathrm{~mm}$ (IQR: $2.2-3.7 \mathrm{~mm}$ ). An overview of the intranodular diameter variation per volume category is shown in table 1 . Intranodular diameter variation for smaller nodules $\left(50-200 \mathrm{~mm}^{3}\right)$ was $2.8 \mathrm{~mm}$ (IQR: $2.2-3.5 \mathrm{~mm}$ ) and was smaller than intranodular diameter variation for larger nodules $\left(200-500 \mathrm{~mm}^{3}\right.$; median $3.6 \mathrm{~mm}$ (IQR: $2.5-5.1 \mathrm{~mm}$ ), $\mathrm{p}<0.01$ ). 
Table 1 Overview of intranodular diameter variation* in baseline nodules per nodule volume category

\begin{tabular}{|c|c|c|c|c|c|}
\hline & Volume $50-100 \mathrm{~mm}^{3}$ & Volume $100-200 \mathrm{~mm}^{3}$ & Volume $200-300 \mathrm{~mm}^{3}$ & Volume $300-400 \mathrm{~mm}^{3}$ & Volume $400-500 \mathrm{~mm}^{3}$ \\
\hline $\mathrm{n}(\%)$ & $1423(63.5)$ & $550(24.6)$ & $159(7.1)$ & $68(3.0)$ & $40(1.8)$ \\
\hline Median diameter variation $(\mathrm{mm})$ & 2.7 & 3.1 & 3.3 & 4.0 & 4.2 \\
\hline IQR (mm) & $2.2-3.3$ & $2.3-4.0$ & $2.4-4.3$ & $2.7-5.6$ & $3.2-6.0$ \\
\hline Diameter variation range $(\mathrm{mm})$ & $0.6-12.3$ & $0.2-10.6$ & $1.5-12.6$ & $1.3-11.8$ & $2-11.3$ \\
\hline Variation $\geq 2 \mathrm{~mm}, \mathrm{n}(\%) \dagger$ & $1174(82.5)$ & $484(88.0)$ & $143(89.9)$ & $62(91.2)$ & $40(100)$ \\
\hline
\end{tabular}

*Intranodular diameter variation was defined as maximum nodule diameter (in any direction) minus minimum nodule diameter (in any direction) through the nodule's centre, as determined by LungCARE.

†The intranodular diameter variation of at least $2 \mathrm{~mm}$ refers to the difference in nodule diameter of $2 \mathrm{~mm}$ between LungRads categories 2,3 and $4 \mathrm{~A}$. ${ }^{1}$

\section{Agreement between diameter-based volume and semiautomated volume}

Bland-Altman plots of the comparison between the semiautomated nodule volume and the volume calculated based on mean and maximum axial diameter are presented in online supplementary figure 1. A per-nodule analysis based on nodule margin is provided in online supplementary table 1 .

\section{DISCUSSION}

We evaluated the correlation of diameter and volume measurement in estimating lung nodule size as imaging biomarker for nodule management. Our study demonstrates a wide range in nodule diameter within nodule volume categories. Nodules with diameter thresholds of $8-10 \mathrm{~mm}$, the diameter range with the highest uncertainty of nodule nature, were represented in each volume category. Furthermore, we showed that using mean or maximum axial diameter to assess nodule volume led to a substantial mean overestimation of nodule volume of $47.2 \%$ and $85.1 \%$, respectively, compared with semiautomated volume (see online supplement). Thus, nodule size is poorly represented by mean or maximum nodule length in any plane.

Accurate estimation of nodule size is important as lung cancer risk increases at larger nodule size and it determines management at initial nodule detection. ${ }^{7}$ The finding that $84.9 \%$ of nodules have an intranodular diameter variation of at least $2 \mathrm{~mm}$, which may transfer them between LungRADS categories 2 (regular screening), 3 (6 month LDCT) and 4A (3 month LDCT or positron emission tomography/CT), ${ }^{1}$ underlines the limitations of diameter measurement for nodule management. In this study, nodule diameters were measured semiautomatically by software, so inaccuracy of human readers and manual calliper placement was not taken into account. Previous research showed that two-dimensional CT measurements of small-to-intermediate size $(<20 \mathrm{~mm})$ are unreliable. ${ }^{8}$ In that study, three serial measurements of maximum transverse diameter of 54 pulmonary nodules were performed by three independent readers. Both intrareader and inter-reader agreement were found to be poor, with a minimum intrareader measurement error of $1.32 \mathrm{~mm}$. In cases where repeated measurements of a single nodule were performed by two different readers, the minimum measurement error increased to $1.73 \mathrm{~mm} .{ }^{8}$ The large intranodule diameter variation as shown in our study likely contributed to this measurement error, besides the inaccuracy of manual diameter measurements.

While it remains uncertain if diameter measurement error occurs inconsistently on repeat scans, it has significant potential to affect nodule management. In the LungRADS guideline for the management of screen-detected nodules, growth (positive screen result) is defined as absolute increase in nodule diameter of $\geq 1.5 \mathrm{~mm}$ between two subsequent screening examinations. ${ }^{1}$ This fixed cut-off lies around the minimum measurement error for a single observer, as shown by Revel et al. ${ }^{8}$ Furthermore, this cut-off is smaller than the median intranodule diameter variation of $2.8 \mathrm{~mm}$ that we found. This may lead to nodules erroneously being classified as growing, with unnecessary work-up as result. On the other hand, true growth may be missed because of inaccurate measurements, leading to delay in work-up and potential worse outcome. In the American College of Chest Physicians guideline, nodule growth is expressed as diameter-based VDT. ${ }^{6}$ Although lung nodules have variable minimum and maximum diameters because they are mostly non-spherical, this does not necessarily imply that bidirectional diameter-based growth assessment will provide a VDT different from a volume-based VDT in all cases. Bidirectional diameter assessment is however only accurately performed with $3 \mathrm{D}$ volumetric software, since manual nodule diameter assessment is extremely inaccurate. Moreover, by using 3D software for accurate bidirectional diameter assessment, the volume of the same nodule is automatically provided. Limitations of our study are provided in the online supplement.

In conclusion, the use of mean or maximum axial diameter to assess the size of intermediate-sized lung nodules leads to a substantial overestimation of nodule volume, compared with semiautomated volumetry. Median intranodular diameter variation exceeds the $1.5 \mathrm{~mm}$ growth cut-off as advocated in screening guidelines such as LungRADS. Size of indeterminate nodules with a semiautomatically measurable volume is poorly represented by nodule diameter; a nodule has an infinite number of diameters, but only one volume. Thus, semiautomated volume is the preferred method for pulmonary nodule size estimation.

\section{Marjolein A Heuvelmans, ${ }^{1}$ Joan E Walter, ${ }^{1}$ Rozemarijn Vliegenthart, ${ }^{1}$ Peter M A van Ooijen, ${ }^{1}$ Geertruida H De Bock, ${ }^{2}$ Harry J de Koning, ${ }^{3}$ Matthijs Oudkerk ${ }^{1}$}

${ }^{1}$ Center for Medical Imaging - North East Netherlands, University of Groningen, University Medical Center Groningen, Groningen, The Netherlands

2Department of Epidemiology, University of Groningen, University Medical Center Groningen, Groningen, The Netherlands

${ }^{3}$ Department of Public Health, Erasmus MC, Rotterdam, The Netherlands

Correspondence to Dr Marjolein A Heuvelmans, Center for Medical Imaging - North East Netherlands, University Medical Center Groningen, Groningen 9713 GZ, Netherlands; m.a.heuvelmans@umcg.nl

Contributors MAH, GHDB, HJdK and MO: involvement in the conception, hypothesis delineation and design of the study. MAH, RV, GHDB, HJdK and MO: acquisition of the data or the analysis and interpretation of such information. MAH, JEW, RV, PMAvO, GHDB, HJdK and MO: writing the article or substantial involvement in its revision prior to submission.

Competing interests Siemens Germany provided four digital workstations and LungCARE for the performance of $3 \mathrm{D}$ measurements of the nodules. Roche diagnostics provided a grant for the performance of proteomics research. The corresponding author had full access to all the data in the study and had final responsibility for the decision to submit for publication.

Ethics approval The Dutch Healthcare Committee and the Medical Ethic Boards of each participating centre. 
Provenance and peer review Not commissioned; externally peer reviewed.

(C) Article author(s) (or their employer(s) unless otherwise stated in the text of the article) 2018. All rights reserved. No commercial use is permitted unless otherwise expressly granted.

- Additional material is published online only. To view please visit the journal online (http://dx.doi.org/ 10.1136/thoraxjnl-2017-210770).

\section{D) Check for updates}

To cite Heuvelmans MA, Walter JE, Vliegenthart $R$, et al. Thorax 2018;73:779-781.

Received 15 July 2017

Revised 3 October 2017

Accepted 9 October 2017

Published Online First 22 October 2017
Thorax 2018;73:779-781.

doi:10.1136/thoraxjnl-2017-210770

\section{REFERENCES}

1 American College of Radiology. Lung CT Screening Reporting and Data System (Lung-RADS). http://www. acr.org/Quality-Safety/Resources/LungRADS (7 Jul 2015)

2 Han D, Heuvelmans M, Vliegenthart R, et al. Influence of lung nodule margin on volume- and diameter-based reader variability in $\mathrm{CT}$ lung cancer screening. $\mathrm{Br}$ J Radiol 2017:20170405.

3 Xu DM, van der Zaag-Loonen HJ, Oudkerk M, et al. Smooth or attached solid indeterminate nodules detected at baseline CT screening in the NELSON study: cancer risk during 1 year of follow-up. Radiology 2009;250:264-72.

4 Heuvelmans MA, Vliegenthart R, Oudkerk M. Contributions of the European trials (European randomized screening group) in computed tomography lung cancer screening. J Thorac Imaging 2015:30:101-7.
5 Han D, Heuvelmans MA, Oudkerk M. Volume versus diameter assessment of small pulmonary nodules in CT lung cancer screening. Trans/ Lung Cancer Res 2017;6:52-61.

6 Gould MK, Donington J, Lynch WR, et al. Evaluation of individuals with pulmonary nodules: when is it lung cancer? diagnosis and management of lung cancer, 3rd ed: American College of Chest Physicians evidence-based clinical practice guidelines. Chest 2013;143:e935-120.

7 Horeweg N, van Rosmalen J, Heuvelmans MA, et al Lung cancer probability in patients with CT-detected pulmonary nodules: a prespecified analysis of data from the NELSON trial of low-dose CT screening. Lancet Oncol 2014;15:1332-41.

8 Revel MP, Bissery A, Bienvenu M, et al. Are two-dimensional CT measurements of small noncalcified pulmonary nodules reliable? Radiology 2004:231:453-8. 